\title{
Cut-off Value for Body Mass Index in Predicting Surgical Success in Patients with Lumbar Spinal Canal Stenosis
}

\author{
Parisa Azimi ${ }^{1}$, Taravat Yazdanian ${ }^{2}$, Sohrab Shahzadi ${ }^{1}$, Edward C. Benzel ${ }^{3}$, \\ Shirzad Azhari ${ }^{1}$, Hossein Nayeb Aghaei ${ }^{1}$, Ali Montazeri ${ }^{4}$ \\ ${ }^{1}$ Functional Neurosurgery Research Center, Shahid Beheshti University of Medical Sciences, Tehran, Iran \\ ${ }^{2}$ School of Medicine, Capital Medical University, Beijing, China \\ ${ }^{3}$ Department of Neurosurgery, Cleveland Clinic Foundation, Cleveland, OH, USA \\ ${ }^{4}$ Mental Health Research Group, Health Metrics Research Centre, Iranian Institute for Health Sciences Research, Academic Center for Education, \\ Culture and Research, Tehran, Iran
}

\section{Study Design: Case-control.}

Purpose: To determine optimal cut-off value for body mass index (BMI) in predicting surgical success in patients with lumbar spinal canal stenosis (LSCS).

Overview of Literature: BMI is an essential variable in the assessment of patients with LSCS.

Methods: We conducted a prospective study with obese and non-obese LSCS surgical patients and analyzed data on age, sex, duration of symptoms, walking distance, morphologic grade of stenosis, BMI, postoperative complications, and functional disability. Obesity was defined as BMI of $\geq 30 \mathrm{~kg} / \mathrm{m}^{2}$. Patients completed the Oswestry Disability Index (ODI) questionnaire before surgery and 2 years after surgery. Surgical success was defined as $\geq 30 \%$ improvement from the baseline ODI score. Receiver operating characteristic (ROC) analysis was used to estimate the optimal cut-off values of BMI to predict surgical success. In addition, correlation was assessed between BMI and stenosis grade based on morphology as defined by Schizas and colleague in total, 189 patients were eligible to enter the study.

Results: Mean age of patients was $61.5 \pm 9.6$ years. Mean follow-up was $36 \pm 12$ months. Most patients (88.4\%) were classified with grades C (severe stenosis) and D (extreme stenosis). Post-surgical success was $85.7 \%$ at the 2 -year follow-up. A weak correlation was observed between morphologic grade of stenosis and BMI. Rates of postoperative complications were similar between patients who were obese and those who were non-obese. Both cohorts had similar degree of improvement in the ODI at the 2-year followup. However, patients who were non-obese presented significantly higher surgical success than those who were obese. In ROC curve analysis, a cut-off value of $\leq 29.1 \mathrm{~kg} / \mathrm{m}^{2}$ for BMI in patients with LSCS was suggestive of surgical success, with $81.1 \%$ sensitivity and 82.2\% specificity (area under the curve, $0.857 ;$ 95\% confidence interval, 0.788-0.927).

Conclusion: This study showed that the BMI can be considered a parameter for predicting surgical success in patients with LSCS and can be useful in clinical practice.

Keywords: Lumbar spinal stenosis; Predicting; Surgical success; ROC curve; Body mass index

Received Jul 25, 2018; Accepted Jul 26, 2018

Corresponding author: Parisa Azimi

Functional Neurosurgery Research Center, Shohada Tajrish Hospital, Shahid Beheshti University of Medical Sciences, Tehran, Iran

Tel: +98-2122749204, Fax: +98-2188265188, E-mail: parisa.azimi@gmail.com 


\section{Introduction}

Lumbar spinal canal stenosis (LSCS) is defined as the narrowing of the lumbar spinal canal [1]. The prevalence of the disease in older age is very high [2], and individuals who are overweight and obese are at a higher risk of developing LSCS [3]. It can cause substantial disability and reduced quality of life [2]. In recent decades, LSCS has become the most common indication for spine surgery [4]. Studies about surgery for lumbar stenosis have demonstrated a good to excellent outcome in most patients [5]. However, limited data exist on surgical outcomes in patients with LSCS who are overweight and obese [6].

In clinical practice and health research, body mass index (BMI) is a widely established proxy to categorize adults on the basis of their weight and height as underweight (thin), normal weight, overweight, and obese [7]. As far as surgery for lumbar stenosis is concerned, the findings obtained from studies on BMI as a predictor for outcome after LSCS surgery are inconsistent $[8,9]$. Hence, the questions that remain are whether an elevated BMI decreases the success rate after surgery for LSCS and what optimal cut-off value of BMI predicts surgical success in patients with LSCS. Therefore, this study aimed to determine the association between BMI and outcome of LSCS surgery and to establish the optimal cut-off value for BMI in predicting surgical success in patients who are obese and non-obese in a prospective study over a 2 -year period. In addition, correlation was assessed between BMI and the morphologic grade of stenosis as defined by Schizas et al. [10]

\section{Materials and Methods}

\section{Patients and data collection}

Between October 2009 and December 2013, consecutive patients with LSCS who received surgery at Imam Hossein Hospital, Shahid Beheshti University of Medical Sciences, Tehran, Iran were enrolled in the study. were enrolled in the study. Clinical data were prospectively collected, and patients were followed up at least for 2 years. All patients met the criteria of classic clinical LSCS. These criteria included clinical symptoms; neurological examinations; and imaging studies including plain radiography, computed tomography (CT), and magnetic resonance imaging (MRI) of the lumbar spine. Patients also had a history of inadequate response to conservative treatment after an appro- priate length of management. In all instances, more than one spine surgeon confirmed the diagnosis. The stenotic level(s) were assessed on the MRI and CT images. There were no restrictions on patient selection regarding LSCS level, age, or other characteristics. Patients with prior lumbar spine surgery, spinal anomalies, and spondylolisthesis were excluded from the study. Demographic data including age, sex, and body weight were recorded. The duration of symptoms (in months) and walking distance (in meters) were recorded. BMI was calculated as weight in kilograms, divided by the square of the height in meters (unit, $\mathrm{kg} / \mathrm{m}^{2}$ ). The BMI categories defined by the World Health Organization are as follows: underweight, $<18.5$ $\mathrm{kg} / \mathrm{m}^{2}$; normal weight, $18.5-24.9 \mathrm{~kg} / \mathrm{m}^{2}$; overweight, $25.0-$ $29.9 \mathrm{~kg} / \mathrm{m}^{2}$; and obese, $\geq 30.0 \mathrm{~kg} / \mathrm{m}^{2}$ [11]. However, for this study we categorized patients into two major groups: nonobese (BMI $<30.0 \mathrm{~kg} / \mathrm{m}^{2}$ ) and obese (BMI $\geq 30.0 \mathrm{~kg} / \mathrm{m}^{2}$ ). Using MRI, the grade of stenosis was determined for each patient. Stenosis was classified using the seven-grade classification scheme (A1, A2, A3, A4, B, C, and D), according to the morphology of the dural sac as observed on $\mathrm{T} 2$ axial MRIs (rootlet/cerebrospinal fluid ratio). As defined by Schizas et al. [10], grade A indicates no or minor stenosis, $\mathrm{B}$ indicates moderate stenosis, $\mathrm{C}$ indicates severe stenosis, and D indicates extreme stenosis. Surgery for patients included laminectomy without fusion at one to two levels, unilaterally or bilaterally, depending on the degree of stenosis. Based on at least 20\% failure rate for surgery, it was estimated that a sample of 152 patients would be sufficient for a study of $80 \%$ power at $5 \%$ significance level. However, 189 patients were recruited for the study.

\section{Oswestry Disability Index}

The Iranian version of the Oswestry Disability Index (ODI) (version 2) was used to assess functionality. The ODI contained 10 items, with the score ranging from 0 to 50 , with higher scores indicating worse condition. The psychometric properties of the Iranian version of questionnaire have been well documented [12]. The ODI score was measured at admission and at last follow-up. Surgical success was defined as a $30 \%$ or more improvement on the ODI score from the baseline [13].

\section{Statistical analysis}

All statistical analyses were performed using PASW SPSS 
Statistics ver. 18.0 software (SPSS Inc., Chicago, IL, USA). BMI was considered a continuous variable for analysis. For parameters describing the patient population, continuous variables were compared using Mann-Whitney $U$-test. Categorical variables were compared using Pearson chi-square test.

Logistic regression was adjusted for age, sex, and BMI. Sensitivity and specificity of BMI as an indicator to predict surgical success were determined with the cut-off value. Receiver operating characteristic (ROC) curve and area under the curve (AUC) for ROCs were obtained by plotting sensitivity against the false-positive rate (1-specificity). Youden index ( $\mathrm{J}$ ) was used to determine the optimal cut-off value of BMI, without considering patients who are obese and non-obese, to predict surgical success $(J=$ sensitivity+specificity-1) $[14,15]$. In addition, Spearman's rank correlation between the morphologic grade of stenosis and BMI was evaluated. A p-value of 0.05 was considered statistically significant.

\section{Ethics}

In consideration of varying reading levels, each participant provided informed verbal consent. The main inves- tigator explained the study to each participant and asked for permission to participate. The decision to participate or not in the study did not influence treatment, and information remained confidential. The Ethics Committee of Shahid Beheshti University of Medical Sciences, Tehran, Iran, approved the study and agreed with the consent procedure.

\section{Results}

Overall, 206 patients were enrolled in the study. At 2-year follow-up, there were five deaths, eight patients could not be contacted, and seven did not complete the questionnaires. Thus, data for 189 patients were analyzed. The characteristics of patients, morphology of the dural sac on MRI, and ODI scores are shown in Table 1. The mean \pm standard deviation (SD) age of patients was $61.5 \pm 9.6$ years (range, $38-82$ years). The mean \pm SD duration for follow-up was $36 \pm 12$ months (range, 24-41 months). One- and two-level stenosis was observed in $59.3 \%(n=112)$ and $40.7 \%(n=77)$ patients, respectively. Most patients (88.4\%) who underwent surgery were identified as having grade $\mathrm{C}$ and grade $\mathrm{D}$ stenosis. Postoperative success was $85.7 \%$ for the 2 -year follow-up. Spear-

Table 1. Demographic data and preoperative status of patients with lumbar spinal stenosis ( $n=189)$

\begin{tabular}{|c|c|c|c|c|}
\hline Characteristic & Total & Non-obese $(\mathrm{BMI}<30.0)$ & Obese (BMI $\geq 30.0$ ) & $p$-value \\
\hline Age (yr) & $61.5 \pm 9.6$ & $61.3 \pm 9.5$ & $62.6 \pm 10.2$ & 0.893 \\
\hline Sex (male) & 41.0 & 40.0 & 44.8 & 0.789 \\
\hline No. of patients & $189(100.0)$ & $160(84.7)$ & $29(15.3)$ & 0.001 \\
\hline \multicolumn{5}{|l|}{ Symptoms } \\
\hline Duration of symptoms (mo) & $45.3 \pm 22.6$ & $45.1 \pm 22.3$ & $46.4 \pm 24.2$ & 0.543 \\
\hline Walking distance (m) & $335.4 \pm 221$ & $341.7 \pm 216$ & $300.2 \pm 248$ & $0.063^{\text {a) }}$ \\
\hline Level stenosis & & & & 0.991 \\
\hline One & $112(59.3)$ & $94(58.8)$ & $18(62.1)$ & - \\
\hline Two & $77(40.7)$ & $66(41.2)$ & $11(37.9)$ & - \\
\hline Morphology grade ${ }^{b)}$ & & & & $0.669^{\mathrm{a})}$ \\
\hline Grade D & $44(23.3)$ & $34(21.2)$ & $8(27.5)$ & - \\
\hline Grade C & $123(65.1)$ & $107(66.9)$ & $18(62.1)$ & - \\
\hline Grade B & $15(7.9)$ & $13(8.1)$ & $2(6.8)$ & - \\
\hline Grade A & $7(3.7)$ & $6(3.7)$ & $1(3.4)$ & - \\
\hline Preoperative Oswestry Disability Index (\%) & $36.6 \pm 7.4$ & $35.8 \pm 7.3$ & $40.7 \pm 8.3$ & 0.001 \\
\hline
\end{tabular}

Values are presented as mean \pm standard deviation, $\%$, or number (\%).

BMI, body mass index $\left(\mathrm{kg} / \mathrm{m}^{2}\right)$.

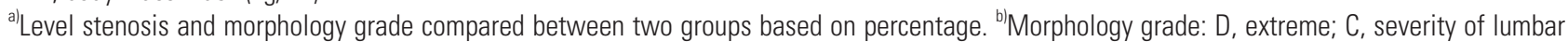
spinal stenosis based on the morphology of the dural sac as observed on T2 axial magnetic resonance imaging. 
Table 2. Logistic regression to predict the probability of surgical success based on variables of age, sex, and BMI

\begin{tabular}{lrrrrr} 
Variable & Standard error & Wald & Significance & Exp(B) & 95\% confidence interval for EXP(B) \\
Age & 0.035 & 3.786 & 0.052 & 1.070 & $1.000-1.146$ \\
BMI & 0.058 & 24.485 & 0.000 & 0.750 & $0.669-0.840$ \\
Sex & 0.516 & 0.766 & 0.381 & 0.639 & $0.234-1.743$ \\
\hline
\end{tabular}

BMI, body mass index $\left(\mathrm{kg} / \mathrm{m}^{2}\right)$.

Table 3. Comparison of pre- and postoperative status and surgical success of patients with lumbar spinal stenosis ( $n=189)$

\begin{tabular}{|c|c|c|c|}
\hline Variable & Non-obese $(B M I<30.0)(n=160)$ & Obese $(B M I \geq 30.0) \quad(n=29)$ & $p$-value \\
\hline Preoperative ODI (\%) & $35.8 \pm 7.3$ & $40.7 \pm 8.3$ & 0.001 \\
\hline Postoperative ODI (\%) & $20.4 \pm 4.5$ & $27.9 \pm 6.3$ & 0.001 \\
\hline ODI change (\%) & 15.4 & 12.8 & 0.02 \\
\hline Surgical success ${ }^{\mathrm{a})}$ & $144(90.0)$ & $19(65.5)$ & 0.001 \\
\hline$p$-value & 0.001 & 0.001 & - \\
\hline
\end{tabular}

Values are presented as mean \pm standard deviation, $\%$, or number (\%).

$\mathrm{BMI}$, body mass index $\left(\mathrm{kg} / \mathrm{m}^{2}\right)$; ODI, Oswestry Disability Index.

${ }^{a} 30 \%$ improvement in ODI was observed over a 2-year period.

man's correlation was weak $(\rho=0.26)$. Logistic regression analysis showed that BMI was significant, while all other variables were not. The results are shown in Table 2.

At baseline and at the 2-year follow-up, the ODI score was significantly higher in patients with obesity than in those who were non-obese. Changes in the ODI score showed a significant difference between patients who were obese and those who were non-obese. The patients who were non-obese experienced significantly greater surgical success than those who were obese. However, on average, both groups achieved significant improvements after surgery. The results are shown in Table 3 .

Overall, dural tear or spinal fluid leak, nerve injury, and wrong level surgery were observed in five, one, and three patients, respectively. No differences were seen between the complication rates of patients who were obese and non-obese. The mean $\pm \mathrm{SD}$ operative time for singlelevel and two-level stenosis in patients who were obese and non-obese was $91 \pm 10$ and $84 \pm 9$ minutes and $111 \pm 12$ and $98 \pm 11$ minutes, respectively. However, there were no significant differences in operative time between the two BMI groups.

According to the ROC analysis, the optimal cut-off value of BMI to predict surgical success was measured as $\leq 29.1 \mathrm{~kg} / \mathrm{m}^{2}$, with $81.1 \%$ sensitivity and $82.2 \%$ specificity (AUC, 0.857; 95\% CI, 0.788-0.927) (Fig. 1).

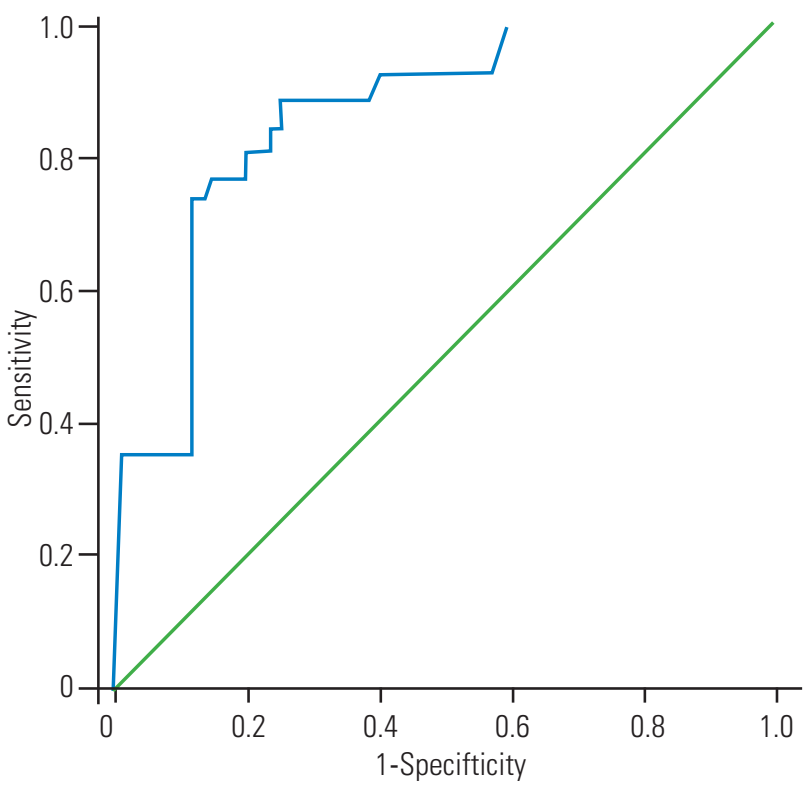

Fig. 1. Receiver operating characteristic curve for body mass index as a predictor of surgical success in patients with lumbar spinal canal stenosis (area under the curve, 0.857 ; 95\% confidence interval, 0.788 $0.927 ; p<0.001$ ). The optimal cut-off value for maximum sensitivity and specificity was 29.1 .

\section{Discussion}

This study demonstrates that BMI effectively reflects surgical success in patients with LSCS. In fact, the optimal 
cut-off value for BMI of $<29.1 \mathrm{~kg} / \mathrm{m}^{2}$ may be a predictive indicator for surgical success rate in patients with LSCS. The results also indicate that patients who are non-obese have greater surgical success than those who are obese.

A systematic review of 21 studies on pre- and post-operative outcomes in LSCS showed that only one study examined the relationship between outcomes after surgical treatment and BMI [16], where no significant association between BMI and outcome was observed [17], perhaps due to different outcome measures and definition of obesity than those used in our study. Using the Roland Morris Score as an outcome measure, a study by Athiviraham et al. [9] found a relationship between BMI and poorer outcome after surgery. However, the findings from studies by Giannadakis et al. [6] and Knutsson et al. [18] were consistent with our findings. They observed that patients with BMI $\geq 30.0 \mathrm{~kg} / \mathrm{m}^{2}$ experienced worse outcomes than patients with $\mathrm{BMI}<30.0 \mathrm{~kg} / \mathrm{m}^{2}$.

The findings from the current study demonstrate that patients undergoing LSCS surgery who are obese and non-obese significantly improve in functionality after surgery; however, patients who are obese experience less improvement than patients who are non-obese based on the ODI score, which is consistent with findings by other studies $[6,18,19]$. No difference in the ODI score change was found between patients who were obese and patients who were non-obese in a study by Rihn et al. [19], whereas in our study and the study by Knutsson et al. [18], a slightly lower ODI score change was observed. This can possibly be explained by the baseline ODI score or inclusion criteria [19]. In contrast, two recent analyses reported similar results for patients who were obese (BMI $\geq 30.0 \mathrm{~kg} / \mathrm{m}^{2}$ ) and patients who were non-obese, with equal or even greater treatment effects among patients with $\mathrm{BMI} \geq 30 \mathrm{~kg} / \mathrm{m}^{2}$ that was largely due to poor outcome in the conservative treatment arm, which introduced a risk for selection bias $[19,20]$. Several studies have used a small number of patients with LSCS, rendering it difficult to make comparisons with the present study $[19,21,22]$. We believe our study is the first showing a significantly greater surgical success rate in patients with BMI cut-off value $<29.1 \mathrm{~kg} / \mathrm{m}^{2}$, thereby providing excellent sensitivity and specificity in predicting surgical success in patients with LSCS. Therefore, a patient's weight is a parameter that can be used to predict surgical success. In our study obesity was defined as $30.0 \mathrm{~kg} / \mathrm{m}^{2}$, but the cut-off value to predict surgical success is $29.1 \mathrm{~kg} / \mathrm{m}^{2}$. Patients with BMI between $29.1 \mathrm{~kg} / \mathrm{m}^{2}$ and $30.0 \mathrm{~kg} / \mathrm{m}^{2}$ are considered nonobese; however, their predicted surgical result is poor. Certainly, the cut-off value of BMI has been calculated for all patients, without considering obese versus non-obese. In addition, obesity can be defined in multiple ways.

We observe a weak correlation between morphologic grade of stenosis and BMI. According to the literature, no previous studies have assessed this issue. In addition, several studies on lumbar spine surgery have shown no difference between the complication rates of patients who were obese and patients who were non-obese [23-25], which is consistent with our findings.

To the best of our knowledge, no previous studies have investigated appropriate cut-off values for BMI indices for the diagnosis of surgical success in patients with LSCS. We believe that ethnic and racial differences in the population in other countries may require different cut-off values for the diagnosis of surgical success. To assess patients with LSCS, there are various factors and measures used to predict surgical success, including a Visual Analog Scale (VAS), the ODI score, radiologic results, and neurological status. In addition, the ODI score is one of the most valuable factors for functional result. However, it is argued that none of these instruments can be considered as a gold standard. Accordingly, we need more specific measures to evaluate patients and to identify ways to improve care. However, additional research is needed to assess the discriminant power of the tools [26].

There are some limitations in our study. First, because this is a cross-sectional study in nature, the results may not be generalizable to other populations. Comprehensive multicenter studies are needed to confirm the absence or presence of generalizability of the findings. Second, the numbers of patients in the two groups are vastly different; however, no significant differences were observed in the two groups based on morphologic grade (Table 2). Therefore, larger studies are needed to confirm our findings. Third, the results were evaluated at 2-year follow-up. A study with longer follow up may provide more clinically relevant information. Fourth, age, sex, self-reported weight, and height may have caused bias in the estimates [27]. Fifth, infection rates, length of stay, and VAS levels for leg and back pain were not assessed in this study. Sixth, medical co-morbidities may impact on the severity of symptoms and surgical outcomes. These should be studied as well, particularly because patients who are obese are more likely to experience these. Seventh, 
preoperative clinical severity in terms of the ODI score was different between patients who are obese and those who are non-obese, which may have caused bias in the results. However, $\geq 30 \%$ improvement from the baseline ODI scores is considered as surgical success. Finally, postoperative weight loss in obese individuals may reduce back and leg pain and improve function $[28,29]$. Further studies are needed to clarify this issue.

\section{Conclusions}

BMI cut-off value of $<29.1 \mathrm{~kg} / \mathrm{m}^{2}$ can be considered as a parameter for predicting surgical success in patients with LSCS and can be useful in clinical practice.

\section{Conflict of Interest}

No potential conflict of interest relevant to this article was reported

\section{Acknowledgments}

The authors thank the staff of the Neurosurgery Unit, Imam-Hossain Medical Center, Tehran, Iran.

\section{References}

1. Kovacs FM, Urrutia G, Alarcon JD. Surgery versus conservative treatment for symptomatic lumbar spinal stenosis: a systematic review of randomized controlled trials. Spine (Phila Pa 1976) 2011;36:E133551.

2. Costandi S, Chopko B, Mekhail M, Dews T, Mekhail N. Lumbar spinal stenosis: therapeutic options review. Pain Pract 2015;15:68-81.

3. Knutsson B, Sanden B, Sjoden G, Jarvholm B, Michaelsson K. Body mass index and risk for clinical lumbar spinal stenosis: a cohort study. Spine (Phila Pa 1976) 2015;40:1451-6.

4. Swedish Society of Spinal Surgeons. Webpage for the Swedish Society of Spinal Surgeons [Internet]. [place unknown]: Swedish Society of Spinal Surgeons [cited 2015 Sep 9]. Available from: http://www.4s.nu/.

5. Turner JA, Ersek M, Herron L, Deyo R. Surgery for lumbar spinal stenosis: attempted meta-analysis of the literature. Spine (Phila Pa 1976) 1992;17:1-8.

6. Giannadakis C, Nerland US, Solheim O, et al. Does obesity affect outcomes after decompressive surgery for lumbar spinal stenosis? a multicenter, observational, registry-based study. World Neurosurg 2015;84:1227-34.

7. Willett WC, Dietz WH, Colditz GA. Guidelines for healthy weight. N Engl J Med 1999;341:427-34.

8. Ain MC, Chang TL, Schkrohowsky JG. Laminectomies and achondroplasia: does body mass index influence surgical outcomes? Am J Med Genet A 2007;143A:1032-7.

9. Athiviraham A, Wali ZA, Yen D. Predictive factors influencing clinical outcome with operative management of lumbar spinal stenosis. Spine J 2011;11:6137.

10. Schizas C, Theumann N, Burn A, et al. Qualitative grading of severity of lumbar spinal stenosis based on the morphology of the dural sac on magnetic resonance images. Spine (Phila Pa 1976) 2010;35:191924.

11. World Health Organization. Webpage for the World Health Organization [Internet]. Geneva: World Health Organization [cited 2018 Sep 22]. Available from: http://www.who.int/news-room/fact-sheets/detail/ obesity-and-overweight.

12. Mousavi SJ, Parnianpour M, Mehdian H, Montazeri A, Mobini B. The oswestry disability index, the roland-morris disability questionnaire, and the quebec back pain disability scale: translation and validation studies of the Iranian versions. Spine (Phila Pa 1976) 2006;31:E454-9.

13. Ostelo RW, Deyo RA, Stratford P, et al. Interpreting change scores for pain and functional status in low back pain: towards international consensus regarding minimal important change. Spine (Phila Pa 1976) 2008;33:90-4.

14. Fawcett T. An introduction to ROC analysis. Pattern Recognit Lett 2006;27:861-74.

15. Hosmer DW, Lemeshow S. Applied logistic regression. 2nd ed. New York (NY): John Wiley \& Sons; 2000.

16. Aalto TJ, Malmivaara A, Kovacs F, et al. Preoperative predictors for postoperative clinical outcome in lumbar spinal stenosis: systematic review. Spine (Phila Pa 1976) 2006;31:E648-63.

17. Javid MJ, Hadar EJ. Long-term follow-up review of patients who underwent laminectomy for lumbar stenosis: a prospective study. J Neurosurg 1998;89:1- 
7.

18. Knutsson B, Michaelsson K, Sanden B. Obesity is associated with inferior results after surgery for lumbar spinal stenosis: a study of 2633 patients from the Swedish spine register. Spine (Phila Pa 1976) 2013;38:435-41.

19. Rihn JA, Radcliff K, Hilibrand AS, et al. Does obesity affect outcomes of treatment for lumbar stenosis and degenerative spondylolisthesis?: analysis of the Spine Patient Outcomes Research Trial (SPORT). Spine (Phila Pa 1976) 2012;37:1933-46.

20. McGuire KJ, Khaleel MA, Rihn JA, Lurie JD, Zhao W, Weinstein JN. The effect of high obesity on outcomes of treatment for lumbar spinal conditions: subgroup analysis of the spine patient outcomes research trial. Spine (Phila Pa 1976) 2014;39:1975-80.

21. Lehto MU, Honkanen P. Factors influencing the outcome of operative treatment for lumbar spinal stenosis. Acta Neurochir (Wien) 1995;137:25-8.

22. Andreshak TG, An HS, Hall J, Stein B. Lumbar spine surgery in the obese patient. J Spinal Disord 1997;10:376-9.

23. Yadla S, Malone J, Campbell PG, et al. Obesity and spine surgery: reassessment based on a prospective evaluation of perioperative complications in elective degenerative thoracolumbar procedures. Spine J 2010;10:581-7.
24. Peng CW, Bendo JA, Goldstein JA, Nalbandian MM. Perioperative outcomes of anterior lumbar surgery in obese versus non-obese patients. Spine J 2009;9:71520.

25. Senker W, Meznik C, Avian A, Berghold A. Perioperative morbidity and complications in minimal access surgery techniques in obese patients with degenerative lumbar disease. Eur Spine J 2011;20:1182-7.

26. Azhari S, Azimi P, Shazadi S, Khayat Kashany H, Nayeb Aghaei H, Mohammadi HR. Surgical outcomes and correlation of the Copenhagen Neck Functional Disability Scale and modified Japanese Orthopedic Association assessment scales in patients with cervical spondylotic myelopathy. Asian Spine J 2016;10:488-94.

27. Gallagher D, Visser M, Sepulveda D, Pierson RN, Harris T, Heymsfield SB. How useful is body mass index for comparison of body fatness across age, sex, and ethnic groups? Am J Epidemiol 1996;143:228-39.

28. Lidar Z, Behrbalk E, Regev GJ, et al. Intervertebral disc height changes after weight reduction in morbidly obese patients and its effect on quality of life and radicular and low back pain. Spine (Phila $\mathrm{Pa}$ 1976) 2012;37:1947-52.

29. Rothberg AE, McEwen LN, Kraftson AT, et al. The impact of weight loss on health-related quality-oflife: implications for cost-effectiveness analyses. Qual Life Res 2014;23:1371-6. 